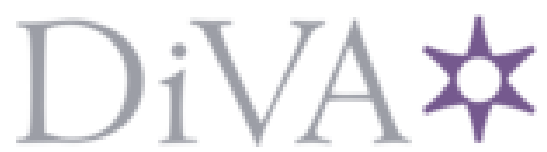

http://www.diva-portal.org

This is the published version of a paper published in .

Citation for the original published paper (version of record):

Westberg, G. (2021)

Affect as a multimodal practice

Multimodality \& Society, 1(1): 20-38

https://doi.org/10.1177/2634979521992734

Access to the published version may require subscription.

N.B. When citing this work, cite the original published paper.

Permanent link to this version:

http://urn.kb.se/resolve?urn=urn:nbn:se:oru:diva-90838 


\title{
Affect as a multimodal practice
}

Multimodality \& Society 202I, Vol. I(I) 20-38

(C) The Author(s) 2021

Article reuse guidelines: sagepub.com/journals-permissions DOI: I0.1 I77/263497952I992734

journals.sagepub.com/home/mas

(SAGE

\author{
Gustav Westberg \\ Örebro University, Sweden
}

\begin{abstract}
This paper sets out a framework for analyzing affect as a multimodal practice. The overall objective is to contribute to the theoretical development of how affect can be approached as an object of semiotic enquiry. The framework is based on the assumption that affect is semiotically materialized through discourse, and with the ambition of taking multimodality seriously, subject formation, strategic perspectivation and affordance are proposed as conceptual starting points for the study of affective meaning-making. Examples are drawn from artifacts and images that represent the Sámi as desirable objects to consumers and tourists. Through a detailed semiotic analysis of a pair of jeans described as being Sámi inspired, and through an analysis of images that promote Sámi tourism experiences, the paper demonstrates how affective ways of being emerge in a relationship between the affordance of semiotic materials and different subjectivities. These insights point to the possibility of further investigating affective subject formation as materialized in diverse semiotic materials in relation to other social phenomena, political issues and ideological concerns.
\end{abstract}

\section{Keywords}

Affect, emotion, affective practice, multimodality, desire, multimodal critical discourse studies, indigenous tourism, indigenous capitalism, Sámi, Sápmi

Within the field of multimodal discourse studies, affect is currently gaining attention as a starting point for investigating how power and social forces are enacted through different modes of communication. In relation to diverse political and social phenomena such as homosocial belonging (Franzèn et al., 2020; Kiesling, 2018), neo-Nazi recruitment

\section{Corresponding author:}

Gustav Westberg, School of Humanities, Education and Social Sciences, Örebro University, Fakultetsgatan I, 70281 Örebro, Sweden.

Email: gustav.westberg@oru.se 
(Westberg, 2021), premium tourism and traveling (Björkvall et al., 2020; Thurlow, 2020), queer- and language activism (Årman, 2020; Milani, 2015) and the rise of right-wing populism (Breeze, 2019; Wodak, 2015), scholars point to the importance of acknowledging multimodal communication for its potential to accomplish affective meaning-making (cf. Milani and Køhler Mortensen, 2020; Wetherell, 2012). The growing body of literature on affect as something that is discursively accomplished, convincingly illustrates that affect is neither "in" nor "outside of" the individual and the social, but rather circulates between different contexts, objects and bodies (Ahmed, 2014: 10). Yet, as Milani and Richardson (2020) contend, there is still a need for semioticians and critical discourse analysts (such as myself, with my background in linguistics) to further explore how affect can be multimodally practiced. Continuing this emerging tradition, this paper proposes a framework for analyzing affect as enacted through multimodal discourse, i.e. through the socially constructed systems of knowledge that signify and organize (some aspect of) reality using multiple modes of communication (Kress and Van Leeuwen, 2001: 4).

The framework identifies subject formation as the point of departure for analyzing affect as a multimodal practice. Inspired by Ahmed (2014) in particular, this implies that the analytical focus is on how discourses can attract, seduce, repel or provoke, thereby making people subject to certain emotions in relation to different social phenomena and political issues. Using data from my ongoing research on indigenous capitalism, the paper will also demonstrate how affective intersubjectivities can be unpacked in contexts in which indigenous cultures are multimodally represented as desirable from a consumer perspective. Critical research on advertising has shown that appeals to consumer's desire to experience something authentic and captivating lies at the heart of the desire to consume (Barthes, 1977; Goldman, 1992; Williamson, 1978). This particularly applies to the various niches of indigenous consumption (Heller and Duchêne, 2012; Viken and Müller, 2017a) in which multimodal discourse is used to commodify indigenous authenticity as desirable. Thus, in this context, authenticity is understood as something that is discursively accomplished through representation rather than as a property that is innate to artifacts or cultures (cf. Heller, 2011: 27-28). As a case in point, affective subject formation will be explored through the multimodal commodification of the Sámi, the only officially recognized indigenous people in the European Union. The traditional Sámi region is called Sápmi and covers Northern Scandinavia and Russia. ${ }^{1}$

In addition to subject formation and intersubjectivity, concepts developed within social semiotics and multimodal critical discourse studies engender important reflection on affect as a multimodal practice. The framework contends that affective meaningmaking cannot simply be deduced from semiotic materials such as artifacts or texts. Rather, the framework argues that an analysis of affective subject formation needs to rely on a detailed semiotic analysis in order to operationalize what Ahmed (2014) called "the emotionality of texts." Methodologically, a critical perspective that sways between engagement and estrangement (Janks, 2010) in combination with the social semiotic concept of affordance (Kress, 2010; Machin, 2016) is elaborated as a conceptual cornerstone of the analysis. This combination allows an investigation of how the situated use of diverse semiotic resources - "the actions and artefacts we use to communicate" (Van 
Leeuwen, 2005: 3) -along with their semiotic possibilities and constraints, prompt certain affective subjectivities.

The overall objective of the paper is to contribute to the theoretical development of how affect can be approached as an object of semiotic enquiry. Stemming from the assumption that affect emerges intersubjectively, it will be demonstrated how an affordance-driven semiotic analysis can be applied to investigate the semiotic enactment of affect when Sámi culture is represented for capitalist purposes in diverse semiotic materials such as items of clothing and images.

In the literature on how indigenous cultures are discursively represented for capitalist purposes, the primary focus has been on how visual, linguistic and material resources are employed to semiotically balance authentic differentiation with global mobility (cf. Pietikäinen and Kelly-Holmes, 2011), whereas the affective dimensions of authentication have been overlooked. Thus, by applying the framework, the paper also attempts to illustrate how an analysis of affect can sensitize the understanding of how discourses on indigenous authenticity works their power not only by promising their consumers "the real thing," but, importantly, also by positioning the consumers through exclusively and positively connoted emotions.

Originally, the intention of this paper was to conduct a field trip to Jokkmokk in the autumn of 2020. Jokkmokk is a village in Sápmi that operates as a fulcrum to Sámi tourism and trade in Sweden. The plan was to compile a semiotic assemblage of multimodal texts, artifacts, interiors, etc. at a designer shop (Sámi Duodji). However, due to the Covid-19 pandemic, the field trip and data collection had to be canceled. This meant that the empirical basis of the paper also had to be heavily revised. I will therefore describe the proposed framework by revisiting texts and artifacts that I have collected over the last couple of years in my research on Sámi commodification. The next section introduces the framework in detail, followed by two brief empirical demonstrations. In conclusion, the paper discusses the insights and takeaways of the framework.

\section{Conceptual framework}

For the framework design, overall inspiration was drawn from the burgeoning field of affective discursive studies (e.g., Fleig and von Scheve, 2020; Wetherell, 2012). The field is sustained by the conviction that affect and emotions are not only of scholarly concern regarding the scrutiny of the somatic, non-discursive and pre-cognitive dimensions of social life. They are also assumed to be fundamentally intertwined with and enacted through meaning-making practice and are therefore relevant to study regarding the diverse ideological, political and social work that they can be discursively mobilized to perform.

The framework is further underpinned by the conviction that affective meaningmaking is not restricted to any specific semiotic mode. Therefore, and with the ambition of "taking the notion of multimodality seriously," it seeks to elaborate concepts that "at some level of generality - apply to and encompass the characteristics and potential of all modes" (Bezemer and Kress, 2016: 6). These concepts are charted in Table 1 and are given in-depth attention in the following sections. 
Table I. Conceptual framework for analyzing affect as a multimodal discourse.

\begin{tabular}{lll}
\hline Subject formation & Strategic perspectivation & Affordance \\
\hline $\begin{array}{l}\text { Refers to the social force of } \\
\text { emotions. }\end{array}$ & $\begin{array}{l}\text { Refers to a technique for } \\
\text { establishing intersubjectivity as } \\
\text { the basis of affective } \\
\text { interpretation. }\end{array}$ & $\begin{array}{l}\text { Refers to the meaning-making } \\
\text { possibilities and constraints of } \\
\text { different semiotic materials. }\end{array}$ \\
$\begin{array}{l}\text { Targets the "affective ways } \\
\text { of being" enabled through } \\
\text { multimodal discourse. }\end{array}$ & $\begin{array}{l}\text { Targets the relationality of } \\
\text { affective subject formation. }\end{array}$ & $\begin{array}{l}\text { Targets the multimodal } \\
\text { materialization of affective } \\
\text { subject formation. }\end{array}$ \\
\hline
\end{tabular}

\section{Affect and critical discourse studies}

The first conceptual issue that calls for clarification concerns the relationship between affect and (multimodal) communication. Affect and emotions are not novel phenomena in public discourse, or in discourse studies, for that matter. Fleig and von Scheve (2020: 3 ) contend that public discourse is, and always has been, a space for affect and emotion as much as for rational deliberation. Tellingly, emotional appeals have long been investigated in rhetoric studies through the concept of pathos. From the perspective of multimodality and semiotics, critical research on, for example, advertising, has illustrated the importance of semiotic and, in particular, visual appeals to the emotional (Barthes, 1977; Cook, 2001; Ledin and Machin, 2018b). Despite this, until recently, affect has been neglected as a starting point in its own right for conducting (multimodal) critical discourse analysis (Glapka, 2019). This is partially because a Habermasian understanding of rationality and deliberation has guided much of the critical work that has been conducted in the name of critical discourse studies (henceforth referred to as CDS). As a consequence, the critical impetus of CDS has generally been to demystify how discourse can contribute to discrimination, social change, as well as to ideological manipulation (Fairclough, 1992; Forchtner, 2011; van Dijk, 1993). This has also been the case when attention have been directed at the affective and the emotional. As an illustrative example, in her seminal study of advertising discourse, Williamson (1978) approaches affective appeals as a means of manipulation and propaganda (cf. Goldman, 1992). Here, however, rationality is not taken as the basis for critique. Rather, the framework strives to explore and contemplate (cf. Spitzmüller and Warnke, 2011) the performative role of emotions in their own right, not to normatively evaluate the affective dimensions of discourse.

Regarding the previous neglection of affect in discourse studies, in her influential work on affective-discursive practice, Wetherell (2012: 19) asserts that the overall affective turn in the social sciences has gained influence because it provides "bored academics" with a new perspective that allows the somatic, pre-discursive and precognitive aspects of social life to be studied. Wetherell (2012: 19) contends that what appears to attract people working within cultural studies to study affect "is that it is not discourse." Thus, scholars like Massumi (1995, 2002) distinguish between affect as individual somatic experiences and reserve the term emotion to signify the cultural 
interpretation of such experiences through discourse (cf. Glapka, 2019). In the present work, however, affect is not separated from emotions as embodied arousals that exist prior to cognition, discourse or semiosis. Affect is instead conceived of as a relational concept that signifies intersubjective experiences and their performative role in the formation of collective subjectivities, identities and belongings through discourse (Franzèn et al., 2020; Milani and Køhler Mortensen, 2020; Motschenbacher, 2020; Westberg, 2021). Put differently, emotions (e.g., anger, desire, hope, disgust, fear, love, pride, shame, etc.) are conceived of as being accomplished, circulated and semiotically materialized in affective-discursive practice.

Departing from Wetherell's (2012:19) definition of affective practice as "a figuration where body possibilities and routines become recruited or entangled together with meaning-making and with other social and material figurations," the framework distinguishes affect and related terms such as emotion and feeling by its emphasis on the social and collective as opposed to the individual. With reference to Burkitt (1997), Wetherell argues that emotions are not "an object inside the self, as basic emotions research assumes" (Wetherell, 2012: 24) but are performed through affective-discursive practice and always emerge in relation to other subjects, to events in the world and as responses to situations and situated meaning-making. On a related note, Motschenbacher (2020) clarifies that affect is "not about the private, internal feelings of individuals, but a mechanism that publicly unites individuals through shared experience." This draws attention to the first key concept of the framework.

\section{Affective subject formation}

This section clarifies the view on affect as working its power through subject formation and intersubjective meaning-making. As explained above, affect is regarded as a practice that pertains to the formation of collective identities and emotional belongings through semiotic materialization. Therefore, multimodal discourse is regarded as being pivotal to the "the formation of bodies and their potential to affect and to be affected in socially meaningful ways" (Fleig and von Scheve, 2020: 6). According to Ahmed (2014: 12), the performativity of emotions lies in their potential to invite and position subjects, and the ability for emotions to "stick" to subjects is associated with the understanding of how emotions "align individuals with communities" and bind subjects together by mediating "the relationship between the psychic and the social, and between the individual and the collective" (Ahmed, 2004: 119). In brief, affective practices articulate certain “emotional ways of being,' and as the empirical examples will illustrate, the commodification of Sáminess enables the desiring of subjects. The "stickiness" of such subject formation hinges on both intersubjective engagement and ideological recognition. Ahmed, again, argues that for a subject to accept the position of a discursively offered "emotional you," it needs to both recognize and reconcile with the representational perspective of the discourse in question. Take the emotion of happiness as an example. For a subject to align with discursive invitations to happiness, it is necessary for the subject to also align with the collective ideal and morality upon which certain objects, actions and experiences - representations of Sámi nature and indigenous people, for instance-are signified as triggers of happiness (Ahmed, 2010). Thus, affective 
positioning is inherently a matter of relational and intersubjective meaning-making in that the semiotic invitations to emotions root the interpreting subject in collective habits and cultural patterns.

The emphasis on intersubjectivity further suggests that an analysis of affective practice cannot merely aim to detect how pre-defined emotions can "land" on subjects through semiotic materialization (Wetherell, 2012: 83-84). Rather, the analysis and interpretation need to push one step further by asking how semiotic subject formation enables intersubjective effects, thereby working its social force. Put differently, an analysis of affective subject formation is not about identifying how affective subject positions are semiotically accomplished, but must also consider what the positions $d o$ in relation to an institution or a social grouping, as well as with respect to the communicative interests and motives of the participants engaged in the communication. This draws attention to the question of how to interpret such intersubjective effects, which is elaborated in the following section.

\section{Strategic perspectivation}

The conceptual considerations outlined above are accompanied by the major methodological challenge of how to encircle affect as an intersubjective phenomenon. This challenge relates to the idea that an analysis of representation can never independently unravel affect. An analysis of how emotions are semiotically materialized through affective-discursive practice needs to be embedded in a relevant intersubjective setting. Such an intersubjective setting can be achieved using different methodologies, for example, ethnography (Årman, 2020), interactional analysis (Franzèn et al., 2020; Kiesling, 2018) or intertextual analysis (Westberg, 2020), as well as through the interpretative technique I choose to call here strategic perspectivation. This technique is inspired by Janks' (2010) work on critical literacy. In particular, the conviction that discourse analysts needs to embrace both critical engagement and estrangement is generative for the current concern. Janks' ideas revolve around critical text analysis, although the ideas developed in the following quote are applicable to all modes of communication:

Critical literacy requires that we both engage with and distance ourselves from texts, which I have described [...] as reading with a text and reading against a text. We have to do both as each on its own is a form of entrapment. Engagement without estrangement is a form of submission to the power of the text regardless of the reader's own positions. Estrangement without engagement is a refusal to leave the confines of one's own subjectivity, a refusal to allow otherness to enter. Without the entry of the other, can we be said to have read the text at all? What then might we be resisting?

By reading with and by buying into the representational perspective of multimodal discourse, I contend it is possible to achieve interpretative validity and contemplate how subject formation is accomplished in relation to the social and the collective. By strategically choosing to engage rather than to estrange (as scholars of CDS tend to do) with affective practices, it becomes possible for the analyst to interpret the social force of affective subject formation from a certain-and ideal-intersubjective relationship. A 
strategic reading that is loyal to and buys into the representations therefore allows the analyst to leave their own subjectivity and to extract the positions that are offered through the situated use of semiotic resources. Thus, the proposed technique is a strategy for considering the social work of emotions and contemplating what subject formation does from a certain intersubjective horizon. A similar approach is adopted by Björkvall et al. (2020), where the spatial semiotics of affect at international airports are interpretated from the perspective of "the ordinary traveler," as well as in Westberg (2021), where I engage with the social force of neo-Nazi propaganda from the perspective of the ideal recruit.

The methodological technique further suggests that by swaying between an engaged and an estranged position, diverse starting points for intersubjective interpretation can be achieved. By allowing diverse subjectivities to guide the analytical work, the "stickiness" of affective subject formation can be understood from different perspectives. Alternative perspectivations will necessarily engender alternative intersubjectivities and will therefore focus on diverse social effects. For instance, the study of neo-Nazi propaganda recently mentioned contends that the propaganda positions the ideal Nazi recruit through emotions such as pride, bravery and hope, whereas the very same propaganda has the potential to engage ideologically reluctant subjects through emotions of fear, anger or worry (Westberg, 2021).

With respect to the empirical focus of this paper, contemporary indigenous commodification is intertwined with diverse affective intersubjectivities pertaining to post-colonialism and capitalism, which are productive as interpretative starting points in their own right. Like the history of other indigenous groups, Sámi history is characterized by colonial dominance by nation states. Contemporary relationships between indigenous people, such as the Sámi and nation states, are characterized by national shame - and a sense of colonial guilt (Ahmed, 2014) in tandem with a sense of rage and anger about colonial discrimination and exploitation combined with pride tend to fuel political struggles among the Sámi regarding their rights, selfdetermination and territorial claims (cf. Lantto and Mörkenstam, 2008). In global markets, feeling proud of indigenous heritage has further evolved into a strategy for economic growth, and within saturated markets, notions of indigenous people are employed through discourse to signify goods and services as "authentic." Tellingly, Sámi traditions are valorized as goods and services in many consumer fields, for example, in the branding of hotels and spa treatments, ${ }^{2}$ in the branding of clothes as inspired by the Sámi lifestyle, ${ }^{3}$ in the marketing of traditional Sámi handicraft, ${ }^{4} \mathrm{cu}-$ linary traditions ${ }^{5}$ and, of course, in heritage tourism (de Bernardi, 2019; Viken and Müller, 2017b). Such acts of commodification continue a tradition from the late 19th century of representing Sàmi people as desirable to audiences that had purchasing power (Baglo, 2011).

Thus, the commodification of Sámi authenticity is approachable from a range of relevant intersubjective perspectivations, which points to the importance of clearly demarcating the basis upon which the social effects of affective subject formation is interpretated. With the purpose of investigating how Sámi authenticity can be represented as an object of desire, I have therefore strategically chosen to take on the perspective of the loyal customer in the empirical part of this paper. 


\section{Affordance}

In order to achieve interpretive validity with regards to how different semiotic materials can be employed to materialize affective subject formation, the framework suggests that strategic perspectivation is combined with the concept of affordance. The concept was originally defined by Gibson (1977) to signify how properties in the environment make possible and constrain different behaviors and actions to humans and other animals. From the perspective of multimodality, Kress (2010) has expanded the concept to encompass all the meaning-making gains and losses that are the consequence of selecting one semiotic resource over another. Thus, an affordance-driven semiotic analysis questions the kind of meaning-making that is prompted through, for instance, images compared to interior design because of their inherent material properties. Within the framework, an affordance is accordingly understood as the prompt of a semiotic material that enables certain affective actions and interpretations.

The theoretical claim that affect is intersubjective further suggests that the potential of semiotic materials to afford affective meaning-making is only partially inherent in the choice of one semiotic material over another. On a related note, Gibson (1977), emphasizes that affordance cuts across the subjective and the objective, which means that an affordance is neither independently inherent in a semiotic material, nor in the eyes of the perceiver. Therefore, the affective affordance of semiotic materials necessarily needs to be approached relationally. Hence, the relevance of strategic perspectivation.

The next section will exemplify the application of the framework with regards to how representations of Sámi authenticity enable affective subject formation. The analysis will be guided by the following question: How does the materiality of a semiotic resource afford certain affective ways of being for an ideal consumer who encounters Sámi authenticity through multimodal discourse?

\section{Sámi authenticity as multimodal affective practice}

As initially claimed, multimodal representations of Sámi authenticity are approached here as an affective practice of desire. Rather than aligning with psychoanalytical understandings of desire in the tradition of Freud and Lacan, the present study continues a cultural theorist approach stemming from the work of Deleuze and Guattari (1987). The main takeaway from Deleuze and Guattari is the conception of desire as not being exclusively a matter of erotic demand and psychological development. Instead, they direct theoretical attention toward the ways in which diverse desires are enabled and how they manifest, move and engage different subjectivities. Cameron and Kulick (2003: 111) emphasize that this orientation is generative for discourse analysts as it "foregrounds desire as something that is continually being dis/re/assembled."

Inspired by Cameron and Kulick's (2003) approach to desire as something that is enacted in and through communication, desire is here perceived as the way that multimodal discourse can be employed to create amusement, excitement, pleasure, thrill or enjoyment in relation to different objects. In this respect, the investigation of desire will be guided by Ahmed's (2010) theorization of objects of desire. Common to all desires, 
Ahmed explains, is what we collectively regard as being attractive and also identify as not having.

A similar approach to desire underpins much Marxist-based critical analysis of advertising, perhaps most notably apparent in Williamson's (1978) classic analysis of advertising as propaganda. However, Ahmed develops the concept of objects of desire to encompass not only consumerism, and explains that desire is "both what promises us something, what gives us energy, and also what is lacking, even in the very moment of its realization" (2010: 31). This understanding enables me to contemplate the intersubjective effects that are at play when Sámi authenticity is represented as desirable.

In order to semiotically investigate how items of clothing and images can afford affective subject formation, tools from social semiotics and multimodal critical discourse are applied. Firstly, the affordance of a pair of high-end designer jeans that are promoted as "Sámi inspired" will be considered. The analysis focuses on how affective subject formation is afforded "in" the jeans through different design choices pertaining to fabric weight and texture in particular (Archer and Westberg, 2020; Bouvier, 2016, 2018).

Secondly, I will demonstrate how the affordance of photographs is used when Sámi places and experiences are represented as desirable objects. In particular, the affordance of images to evoke wider cultural associations without the need to specify that "this sign signifies this or that value" will be considered (Machin, 2016). In this respect, the analysis will primarily draw on Barthesian notions of denotation and connotation (Barthes, 1977)

Lastly, I must reiterate that affective affordances are never independently inherent in semiotic resources. They are realized in the relationship between the material and the subjective. Thus, retracting affective subject formation inevitably involves interpretative work and a need for analysts to label the emotional ways of being that are afforded. However, the labeling itself is not the endpoint of the analysis, but a means of contemplating what affective meaning-making does in relation to different social belongings and institutions.

\section{Authentic clothing, embodied desire}

The first example revolves around a pair of high-end designer jeans produced by the Swedish brand Sarva. ${ }^{6}$ The brand is operated as a family business and was founded by two brothers. On its Facebook page, the brand describes itself as bringing "Swedish produced jeans and Sami related Outdoor products to the world." Further, Sámi heritage is evoked to signify the jeans as "authentic." The founders claim to "have been working very close with our family and relatives with these products to get everything right: details, function and durability." Ultimately, the jeans are said to have been designed to withstand the "hard conditions and extreme cold" of Sámi nomad life.

Before the affordances of the jeans are analyzed as materialized affective practice, they need to be put in perspective as a commodity from a specific intersubjective horizon. The brand targets the high-end spectrum of the jeans market, in which tradition and heritage pertaining to denim production and jeans design constitute core values. From the perspective of the loyal consumer, i.e. the position of a jeans connoisseur who is willing to pay SEK 2200 (around EUR 220) for a pair of Sámi inspired jeans, design is 

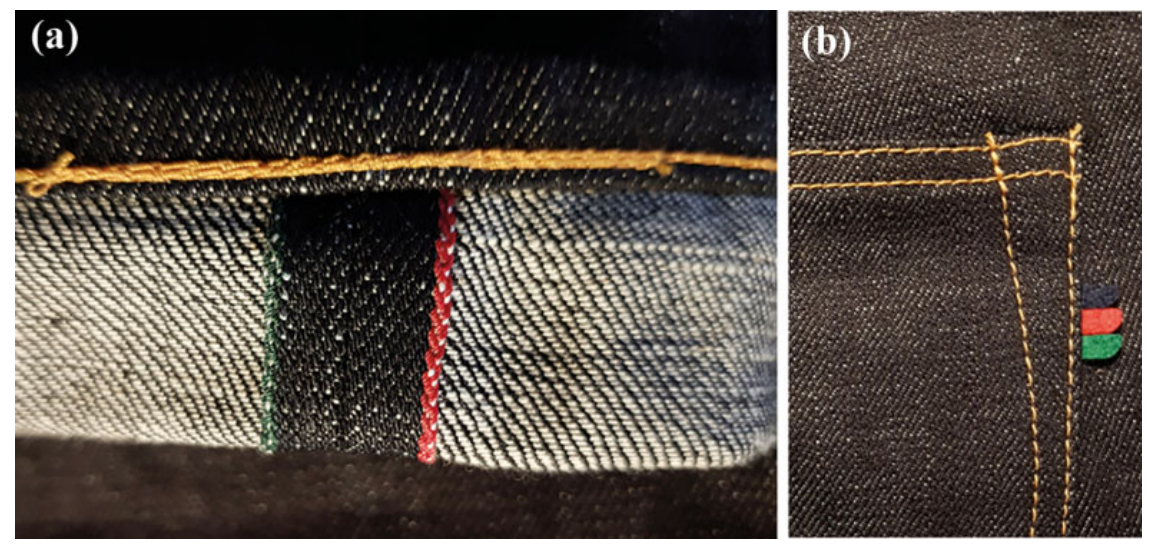

Figure I. Selvage in the color of the Sámi flag. Photograph: Gustav Westberg.

a crucial matter. In the global discourse of designer jeans, jeans are conceived of as the original workwear garment and are entrenched in narratives about craftmanship and the workwear heritage of cowboys, lumberjacks and mine workers (Archer and Westberg, 2020). Perhaps the most crucial design feature for signifying high-end denim craftsmanship is the non-frayed selvage of the fabric, which is the result of weaving the fabric on specific shuttle looms from the early 20th century. Further, selvage in combination with a thick, unwashed indigo-dyed garment, hidden rivets, back stitching and a "classic" fit, signify a premium jeans design (Keet, 2011). In the design of its flagship model "Riekte Sami Selvedge," Sarva combines such designer conventions with design features that signify "Sáminess" and "indigenousness": the selvage seam is made in the colors of the Sámi flag (red, blue, green) (Figure 1) and the leather patch on the back of the jeans is engraved with a ceremonial figure that is prominent within the iconography of Sami religion. In addition, patterns connoting "indigenous art" are engraved on the buttons and printed on the interior cloth of the jeans (Figure 2).

The main affective affordance of the jeans is materialized in the fabric and its properties, and by swaying between estrangement and engagement, it becomes clear that the affordance of the jeans renders diverse affective effects. When holding a pair of new Sarva jeans in your hands, the most notable property is their stiffness, which is the result of the fabric weight and the non-prewashed and raw indigo-dyed fabric. The jeans are made from $14 \mathrm{oz}$. denim, ${ }^{8}$ which is classified as a heavyweight fabric in the global discourse of designer jeans. ${ }^{9}$ Heavy fabric has the potential to signify "substance, durability and functionality" (Bouvier, 2016: 375), and the affordance of the weight and stiffness restricts the garment from being creased or ruffled. In addition to garment weight, the texture (Figure 3) of the jeans is tightly woven, opaque and dense, as well as hard and grainy (cf. Djonov and Van Leeuwen, 2011). The affordance of these properties makes the fabric durable and makes it resistant to intrusive materials, as well as it restricts the fabric from allowing air to permeate (cf. Bouvier, 2018). 

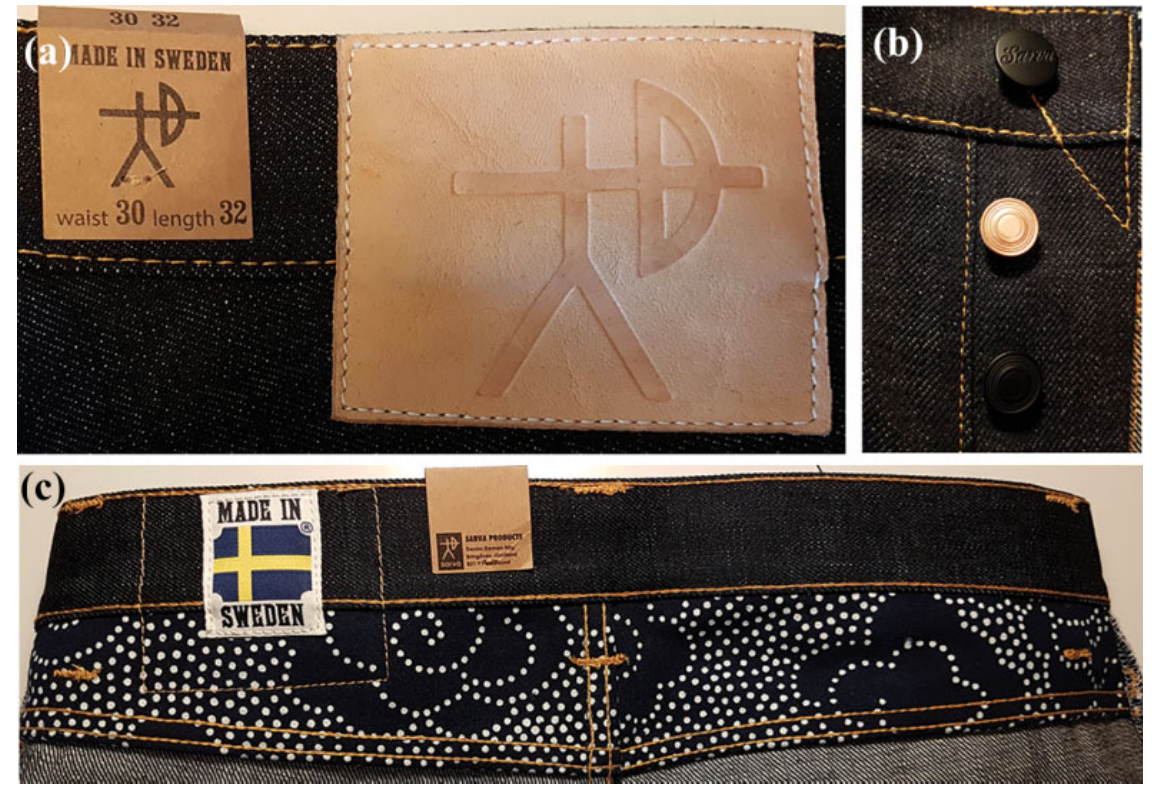

Figure 2. Ceremonial figure and patterns. Photograph: Gustav Westberg.

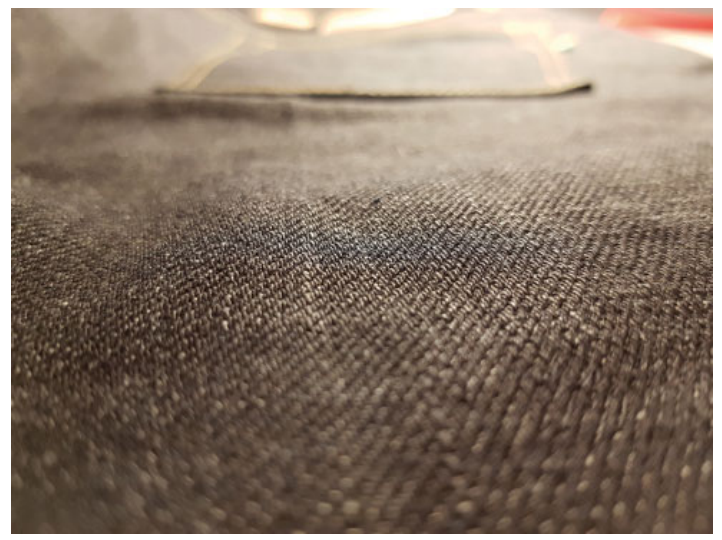

Figure 3. Close-up of denim texture. Photograph: Gustav Westberg.

From the perspective of an estranged consumer who is unfamiliar with the designer practices relating to high-end denim and its heritage, the weight and stiffness of the fabric along with its texture prompt an affective engagement with the jeans through embodied discomfort. When wearing the jeans for the first time, the stiffness of the 
fabric affords restricted mobility - it is hard to move around in them. It is hard to bend your knees and the garment "cuts" into the waist and the back on the knees. The texture of the fabric further restricts the garment from "breathing" and, together with the weight and stiffness, the material properties afford a sense of embodied entrapment.

By shifting from the estranged wearer to the perspective of the engaged and ideal jeans connoisseur who recognizes the garment's properties as a sign of "authentic" denim design, the very same affordances have different affective effects. Rather than engendering a sense of unwearability and emotions of discomfort and entrapment, the jeans emerge as desirable for a customer who idealizes craftmanship and garment design that is in contradistinction to throwaway fashion culture. From the intersubjective perspective of the engaged position, the fabric weight and stiffness do not afford discomfort, but rather prompt the wearer to make them smooth and comfortable by breaking them in through prolonged use. Thus, the affordance of the jeans emerges as a promise of durable comfort, which is supported by the fact that the comfort is absent, even in the realization of its promise. In Ahmed's term, the jeans become an object of desire. The promise of the jeans is therefore inherent in their material properties, yet only in relation to those subjects who align themselves with a global discourse of jeans production in which the purpose of jeans design is conceived of as creating a garment that can withstand the needs of cowboys, lumberjacks and mine workers or, as Sarva claims, the "hard conditions and extreme weather" of Sámi nomad life. ${ }^{10}$

\section{Desiring Sápmi visually}

This section reflects on how the affordance of photographs is employed to represent Sápmi as a desirable tourism experience on the website of Swedish Lapland (henceforth referred to as SL). SL is the predominant actor in marketing indigenous experiences in Sweden and there is both a Swedish and an English version of the website. SL operates as a consortium comprising Norrbotten county and the municipalities of Skelleftea and Sorsele in the upper north of Sweden. Its aim is to "support the industry's ambitions to use international and domestic demand for the destination's supply of sub-arctic products and experiences to do business by providing a cooperative platform based on trade and industry." 11 On its website, Sámi culture is given its own section called Experience Sámi culture first hand with the aim of instilling a desire to travel to Sápmi and experience Sámi culture through consumption. ${ }^{12}$

The focus here is on how visual representations of the nature of Sápmi make the ideal reader subject to desirable emotions of peace, calmness and freedom. The analysis is rooted in the visual excerpt in Figure 4.

The image in Figure 4 represents a setting that is typically depicted when Sápmi is represented in discourse for capitalist reasons: we see a panoramic vista of nature that bears no sign of human impact. The nature comprises rolling hills, cloud-covered mountain peaks, low vegetation and a green, sunlit landscape. Within this setting, a woman wearing hiking boots, jeans and a white knitted cardigan is shown lying on her back on the bare ground, with her eyes closed and her face muscles relaxed. The woman is shown with a backpack under her head and a hat perched on her raised knee. In the text from where the image was taken, the woman is described as a "model" who has visited the site 


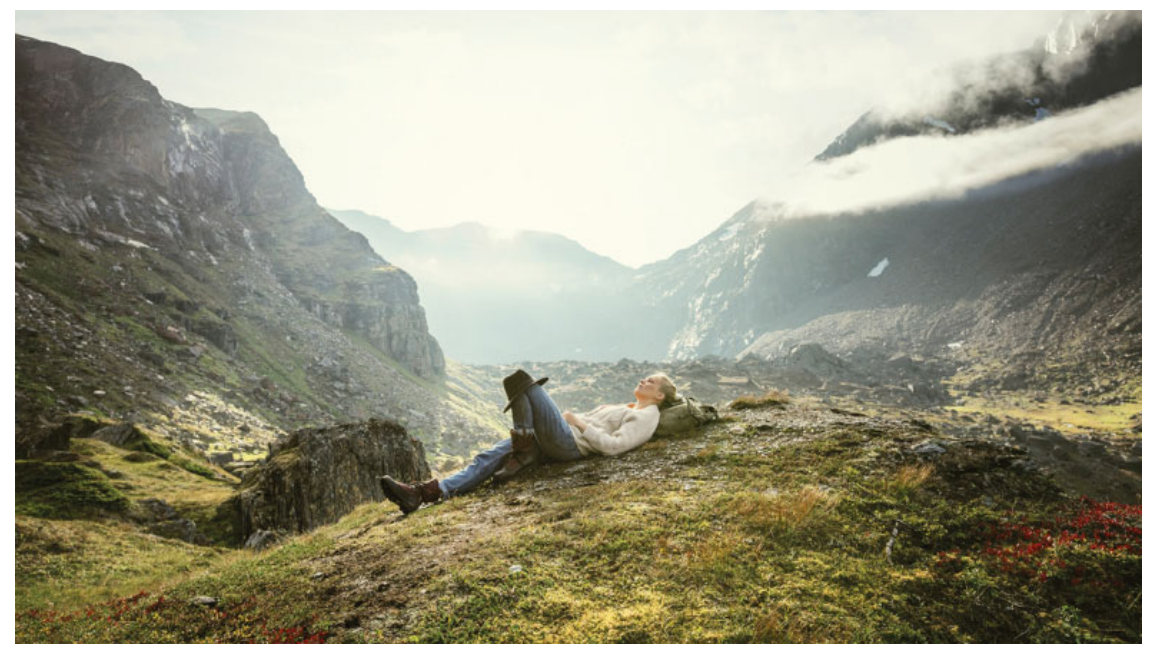

Figure 4. Sápmi as an object of peace, calmness and freedom. Photograph: Andy Andersson. Reproduced with permission from Swedish Lapland.

in question together with the photographer of the image. ${ }^{13}$ The depicted setting and woman are further represented by means of high color saturation and backlight from the sun, which is partially hidden behind the mountain in the top center of the picture.

A key affordance of photographs is to communicate values without explicating that "this sign signifies this or that value" (Barthes, 1977; Machin, 2016). Thus, by putting the image into the perspective of a transient reader who visits SL for inspiration, it can be argued that the denotations ("what we see") in the image resonate with a photographic canon of use (Ledin and Machin, 2018a), i.e. regularities that have developed over time and space when semiotic resources have been used for the (capitalist) purpose of connoting certain ideas, values and moods (Barthes, 1977). Specifically, it can be argued that the resources exemplified in Figure 4 draw on a commercial canon in which denotative representations of seemingly unspoiled and uninhabited nature together with semiotic resources, such as high visual saturation and backlight, have been developed to construe nature as an object of desire. However, as demonstrated in the analysis of the Sarva jeans, affective subjectivities are not inherently "in" any semiotic material but emerge in a relationship between an affordance and different subjectivities. Thus, the affective interpretation of the connotations of Figure 4 needs to be embedded in a relevant intersubjective setting.

The image can be further considered in relation to the spatial resources being depicted, given the affective affordance of spatiality. The panoramic view of Sápmi conveys the impression that nature is endless and eternal; the landscape appears to "go on" forever with no horizontal planes combined with only "natural" vertical planes of mountains that demarcate the depicted space. In the terminology proposed by Stenglin (2008), Sápmi emerges as a strongly unbound space that affords freedom (rather than, for 
example, claustrophobia). Yet, by taking on the perspective of an estranged position, the represented spatial resources might instead connote exposedness or insecurity (Stenglin, 2008: 428).

By hanging on to an engaged position, the representation of Sápmi as a site that bears no sign of human impact feeds into a collective lifestyle discourse where unspoiled nature is anticipated as a site for recreation (cf. Westberg and Årman, 2019). For instance, it is possible to trace this visually coded anticipation of nature in stock images in commercial image banks such as Getty Images (cf. Zieba, 2020). Tellingly, the separate search tags "nature," "peace," "calmness" and "freedom" generate images that clearly resonate with the resources that constitute the image in Figure 4. Furthermore, common to the representation in Figure 4 and the generated images in Getty Images is how the deployment of saturation, backlight and a woman on her own in a relaxed posture contributes to universalizing the affective connotations as "cross-cultural understandings" (Thurlow and Aiello, 2007: 330).

Finally, the connoted values of freedom, peace and calmness are obviously augmented by the representation of the woman. Altogether, her body posture and relaxed facial expression convey the impression that she is resting or sleeping (cf. Thurlow, 2020). The emplacement of the relaxing woman thereby contributes to signifying Sápmi as a place for peaceful relaxation.

Considering these observations as a realization of the imagined reader's desire enables the contemplation of the performative power of the affective subject formation. Firstly, the canonical resemblance to visual representations of peace and freedom from elsewhere invites the reader to share a common lifestyle desire for nature as a generalized and beautified site for recreation and freedom. This points to how the affordance of photographs in connoting meanings prompts the subject to align with collective ideals and certain social belongings.

Secondly, the afforded subject formation needs to be considered as an object of desire, i.e. as something that we collectively regard as being attractive and identify ourselves as not having. Regarding the possibility of recognizing the nature in Figure 4 as desirable, the resonance of the visual imagery of Sápmi in stock images can be said to direct the perceived consumer's anticipation of nature as a promise of what they can expect to miss. Following this line of thought, the visual representations of Sápmi nature are accompanied by the promise of an overall sedate satisfaction, a promise that positions the perceived consumer as not being able to experience a sense of peace, freedom and calmness in the present. The power of the afforded affects lies in the intersubjective positioning of the reader as missing out on something and therefore desiring certain affective sensations. In order for the connoted affects to function as an object of desire, not only do emotions need to be recognized as being reachable through consumption; the positioning power of desire also hinges on the assumption that the reader is entrenched in contra-emotions such as stress and entrapment.

Lastly, these brief observations provide a basis upon which to contemplate the ideological role of affect in indigenous capitalism. When Sápmi is represented as desirable through invitations to peacefulness, calmness and freedom, the perceived consumer and tourist are prompted to feel captivated and to encounter the Sàmi and Sápmi in a straightforward and enjoyable manner. However, this affective subject formation not 
only enables positive emotions, it also constrains engagement in any disturbing, conflicting or uncomfortable emotions that are associated with the post-colonial heritage of the Sámi, in particular those of (colonial) guilt and (national) shame and anger directed at the colonial exploitation of Sápmi. This indicates that the actors in indigenous capitalism appear to be incarcerated in an affective iron cage. With the aim of promoting indigenous culture as something attractive and desirable, issues and aspects of indigenous heritage that might engender strenuous affective engagement are suppressed because they might be hard to promote as desirable. Thus, authenticity appears to cast its affective spell on consumers by detaching them from experiences that would interfere with their discursive conception of the indigenous as something that is purely pleasurable. However, it would be possible to further investigate these affective positions from the perspective of an estranged position.

\section{Concluding remarks}

This paper has presented a framework that allows affect to be investigated as a multimodal practice. Rather than approaching multimodal appeals to affect as a form of ideological manipulation that disrupts deliberation, emphasis has been placed on the social work of emotions in their own right. Departing from an understanding of affect as being enabled through discourse, the technique of strategic perspectivation in combination with the concept of affordance has been developed to encompass affective meaningmaking as it can be potentially materialized through the properties of all modes of communication. This combination points to the key takeaway from the framework: affect is enacted relationally between the affordance of a semiotic material and different subjectivities and social belongings.

From the perspective of multimodal discourse studies, the framework allows the further investigation of how the material properties of semiotic materials and artifacts - e.g. the color, taste and smell of food (cf. Pennycook, 2018: 10) — can be approached as an affective practice. Thus, the framework can hopefully facilitate future investigations into how affective practice can materialize in relation to diverse social phenomena, political issues and ideological concerns beyond the mode of representation alone.

\section{Declaration of Conflicting Interests}

The author(s) declared no potential conflicts of interest with respect to the research, authorship, and/or publication of this article.

\section{Funding}

The author(s) received no financial support for the research, authorship, and/or publication of this article.

\section{Notes}

1. http://www.samer.se/samernaisiffror; https://www.iwgia.org/en/sapmi.html

2. https://ripan.se/spa/spabehandlingar/; https://hotelarcticeden.se

3. https://shop.stoorstalka.com/sv/sidor/allmanna-villkor.html 
4. http://www.samer.se/duodji

5. http://www.sameslojdstiftelsen.com/; http://www.slowfoodsapmi.com/

6. I am grateful to Sarva for supplying me with a pair of jeans for analytical purposes.

7. https://www.facebook.com/sarvaoutdoor/

8. http://sarva.se/shop/denim/riekte-sami-selvedge/

9. https://www.levi.com/US/en_US/features/denim-dictionary

10. http://sarva.se/history/

11. https://www.swedishlaplandvisitorsboard.com/en/the-destination/about-swedish-lapland-visi tors-board/

12. https://www.swedishlapland.com/things-to-do/experience-sami-culture/

13. https://www.swedishlapland.com/stories/karkevagge-the-secret-stone-valley/

\section{References}

Ahmed S (2004) Affective economies. Social Text 22(2): 117-139.

Ahmed S (2010) The Promise of Happiness. Durham, NC: Duke University Press.

Ahmed S (2014) The Cultural Politics of Emotion. Reprinted. Edinburgh: Edinburgh University Press.

Archer A and Westberg G (2020) Establishing authenticity and commodifying difference: a social semiotic analysis of Sámi jeans. Visual Communication. DOI: 10.1177/1470357219896819.

Årman H (2020) Affects of verbal hygiene: the impact of language activism at a Swedish high school. Language Policy 1-21. DOI: 10.1007/s10993-020-09543-3.

Baglo C (2011) Pa ville veger? Levende utstillinger av samer i Europa og Amerika. Tromsø: Universitetet i Tromsø. Available at: https://munin.uit.no/handle/10037/3686 (accessed 3 September 2019).

Barthes R (1977) Image, Music, Text. London: Fontana Press.

Bezemer JJ and Kress GR (2016) Multimodality, Learning and Communication: A Social Semiotic Frame. London New York, NY: Routledge, Taylor \& Francis Group.

Björkvall A, Van Meerbergen S and Westberg G (2020) Feeling safe while being surveilled: the spatial semiotics of affect at international airports. Social Semiotics 1-23. DOI: 10.1080/ 10350330.2020.1790801.

Bouvier G (2016) Discourse in clothing: the social semiotics of modesty and chic in hijab fashion. Gender and Language 10(3): 364-385.

Bouvier G (2018) Clothing and meaning making: a multimodal approach to women's abayas. Visual Communication 17(2): 187-207.

Breeze R (2019) Emotion in politics: affective-discursive practices in UKIP and Labour. Discourse \& Society 30(1): 24-43.

Burkitt I (1997) Social relationships and emotions. Sociology 31(1): 37-55.

Cameron D and Kulick D (2003) Language and Sexuality. Nachdr. Cambridge: Cambridge University Press.

Cook G (2001) The Discourse of Advertising, 2nd edn. The Interface series. London New York, NY: Routledge.

de Bernardi C (2019) Authenticity as a compromise: a critical discourse analysis of Sámi tourism websites. Journal of Heritage Tourism 14(3): 249-262. 
Deleuze G and Guattari F (1987) A Thousand Plateaus: Capitalism and Schizophrenia. Minneapolis, MN: University of Minnesota Press.

Djonov E and Van Leeuwen T (2011) The semiotics of texture: from tactile to visual. Visual Communication 10(4): 541-564.

Fairclough N (1992) Discourse and Social Change. Cambridge ; Cambridge, MA: Polity Press.

Fleig A and von Scheve C (2020) Public spheres of resonance: constellations of affect and language. In: Fleig A and von Scheve C (eds) Public Spheres of Resonance: Constellations of Affect and Language. Routledge studies in affective societies. Abingdon, Oxon ; New York, NY: Routledge, pp. 1-16.

Forchtner B (2011) Critique, the discourse-historical approach, and the Frankfurt School. Critical Discourse Studies 8(1): 1-14.

Franzèn AG, Jonsson R and Sjöblom B (2020) Fear, anger and desire: affect and the interactional intricacies of rape humor on a live podcast. Language in Society 1-24.

Gibson JJ (1977) The theory of affordances. In: Shaw R and Bransford J (eds) Perceiving, Acting, and Knowing: Towards an Ecological Psychology. Hoboken, NJ: John Wiley \& Sons Inc.

Glapka E (2019) Critical affect studies: on applying discourse analysis in research on affect, body and power. Discourse \& Society 30(6): 600-621.

Goldman R (1992) Reading Ads Socially. London ; New York, NY: Routledge.

Heller M (2011) Paths to Post-Nationalism: A Critical Ethnography of Language and Identity. Oxford studies in sociolinguistics. New York, NY: Oxford University Press.

Heller M and Duchêne A (2012) Pride and profit: changing discourses of language, capital and nation-state. In: Duchêne A and Heller M (eds) Language in Late Capitalism: Pride and Profit. Routledge critical studies in multilingualism. New York, NY: Routledge, pp. 1-21.

Janks H (2010) Literacy and Power. Language, Culture, and Teaching. New York, NY: Routledge.

Keet P (2011) Making new vintage jeans in Japan: relocating authenticity. Textile 9(1): 44-61.

Kiesling SF (2018) Masculine stances and the linguistics of affect: on masculine ease. NORMA 13(3-4): 191-212.

Kress GR (2010) Multimodality: A Social Semiotic Approach to Contemporary Communication. London New York, NY: Routledge.

Kress GR and Van Leeuwen T (2001) Multimodal Discourse: The Modes and Media of Contemporary Communication. London: Arnold.

Lantto P and Mörkenstam U (2008) Sami rights and Sami challenges: the modernization process and the Swedish Sami movement, 1886-2006. Scandinavian Journal of History 33(1): 26-51.

Ledin P and Machin D (2018a) Doing Visual Analysis: From Theory to Practice. Thousand Oaks, CA: Sage.

Ledin P and Machin D (2018b) New codifications, new practices: the multimodal communication of CrossFit. In: Zhao S, Djonov E, Björkvall A, et al. (eds) Advancing Multimodal and Critical Discourse Studies: Interdisciplinary Research Inspired by Theo van Leeuwen's Social Semiotics, 1st edn. Routledge studies in multimodality 19. New York, NY: Routledge, pp. 147-163.

Machin D (2016) The need for a social and affordance-driven multimodal critical discourse studies. Discourse \& Society 27(3): 322-334.

Massumi B (1995) The autonomy of affect. Cultural Critique 31: 83-109. 
Massumi B (2002) Parables for the Virtual: Movement, Affect, Sensation. Post-contemporary interventions. Durham, NC: Duke University Press.

Milani T (2015) Sexual cityzenship: discourses, spaces and bodies at Joburg Pride 2012. Journal of Language and Politics 14(3): 431-454.

Milani TM and Køhler Mortensen K (2020) Intersectionality, affect and discourse. In: De Fina A and Georgakopoulou A (eds) The Cambridge Handbook of Discourse Studies, 1st edn. Cambridge: Cambridge University Press, pp. 417-436.

Milani TM and Richardson JE (2020) Discourse and affect. Social Semiotics 1-6. DOI: 10.1080/ 10350330.2020 .1810553$.

Motschenbacher H (2020) Affective regimes on Wilton Drive: a multimodal analysis. Social Semiotics 1-20. DOI: 10.1080/10350330.2020.1788823.

Pennycook A (2018) Posthumanist Applied Linguistics, 1st edn. London ; New York, NY: Routledge/Taylor \& Francis Group.

Pietikäinen S and Kelly-Holmes H (2011) The local political economy of languages in a Sámi tourism destination: Authenticity and mobility in the labelling of souvenirs. Journal of Sociolinguistics 15(3): 323-346.

Spitzmüller J and Warnke IH (2011) Discourse as a "linguistic object": methodical and methodological delimitations. Critical Discourse Studies 8(2): 75-94.

Stenglin M (2008) Binding: a resource for exploring interpersonal meaning in three-dimensional space. Social Semiotics 18(4): 425-447.

Thurlow C (2020) Beyond the managed heart? Seduction, subjugation and the symbolic economies of sleep. Social Semiotics 1-17. DOI: 10.1080/10350330.2020.1810543.

Thurlow C and Aiello G (2007) National pride, global capital: a social semiotic analysis of transnational visual branding in the airline industry. Visual Communication 6(3): 305-344.

van Dijk TA (1993) Principles of critical discourse analysis. Discourse \& Society 4(2): 249-283. Van Leeuwen T (2005) Introducing Social Semiotics. London: Routledge.

Viken A and Müller DK (2017a) Indigenity and Indigenous Tourism. In: Viken Arvid and Müller DK (eds) Tourism and Indigeneity in the Arctic. Bristol: Channel View Publications.

Viken A and Müller DK (2017b) Tourism and Indigeneity in the Arctic. Bristol: Channel View Publications.

Westberg G (2020) Corona, vaghet och skam: om myndighetskommunikation och affekt på sociala medier. Sprak \& stil NF 30: 5-31. DOI: 10.33063/diva-427673.

Westberg G (2021) Affective rebirth: Discursive gateways to contemporary national socialism. Discourse \& Society 32(2): 214-230. DOI: 10.1177/0957926520970380.

Westberg G and Årman H (2019) Common sense as extremism: the multi-semiotics of contemporary national socialism. Critical Discourse Studies 16(5): 549-568.

Wetherell M (2012) Affect and Emotion: A New Social Science Understanding. Los Angeles, CA London: SAGE.

Williamson J (1978) Decoding Advertisements: Ideology and Meaning in Advertising. Ideas in progress. London: Boyars: Distributed by Calder and Boyars.

Wodak R (2015) The Politics of Fear: What Right-Wing Populist Discourses Mean. Los Angeles, CA: Sage.

Zieba A (2020) Visual representation of happiness: a sociosemiotic perspective on stock photography. Social Semiotics 1-21. DOI: 10.1080/10350330.2020.1788824. 


\section{Author biography}

Gustav Westberg has a PhD in Scandinavian Languages and is an Associate Professor in Swedish Language at Örebro University, Sweden. His research is rooted in multimodal critical discourse analysis and currently revolves around the material and affective dimensions of discourses of authenticity and political extremism. His research is published in journals such as Discourse and Society, Social Semiotics, Visual Communication and Critical Discourse Studies. 